\title{
INVESTIGATE COPING AMONG WOMEN UNDERGOING HYSTERECTOMY \\ ${ }^{1}$ Ekram Sabry Mostafa, ${ }^{2}$ Kamilia Ragab Abo Shabana, \\ ${ }^{3}$ Soad Abd Esalam Ramadan , ${ }^{4}$ Hend Abdallah EI Sayed \\ ${ }^{1}$ Clinical Instructor, Mansoura University, Egypt. \\ ${ }^{2}$ Prof. of Maternal and Neonatal Health Nursing, Faculty of Nursing, Ain shams University \\ ${ }^{3}$ Assistant Professor of Obstetrics and Gynecological Health Nursing, Faculty of Nursing - Bnha University \\ ${ }^{4}$ Lecturer of Obstetrics and Gynecological Health Nursing, Faculty of Nursing, Benha University elalamia2004@gmail.com
}

Abstract

Hysterectomy is the surgical removal of the uterus and it is the most common major gynecological surgical procedure worldwide and have significant impact on women's quality of life and coping pattern. Aim of the present study was to evaluate the coping style for women's undergoing hysterectomy. Research design: A descriptive design was used to achieve the aim of the study. Sample size: It consisted of 100 women with hysterectomy. Setting: It was conducted in the gynecological department at Benha University Hospital. Tools: Three tools were used to collect data, 1) Structured interviewing schedule to assess women's condition, 2) An assessment sheet for women knowledge regarding hysterectomy, and 3) Jalowiec coping scale. Results: It showed that, the majority $(88.0 \%)$ of studied subjects had incorrect knowledge about hysterectomy. It also revealed that, the high use of coping styles was highest for supportive as $55.0 \%$. The moderate use of coping styles was highest for optimistic, self-reliant, evasive, and fatalistic styles as $71.0 \%, 64 \%, 57 \%$ and $50 \%$ respectively. The low use of coping styles was highest for emotive, confirmative and palliative styles as $95 \%, 64 \%$ and $58 \%$ respectively. there were no statistically significant relation between women's knowledge and fatalistic, evasive and supportive coping styles, while there were a statistical significant relation between women's knowledge and optimistic coping and emotive coping styles. there were highly a statistical significant relations between women's knowledge and palliative, confirmative and self-reliant coping styles. Conclusion hysterectomy has more effect on women's coping pattern Recommendations: An educational program should be conducted to improve knowledge and coping pattern for women's with hysterectomy.

Key words: Hysterectomy, Coping pattern, Knowledge, Assessment

\section{Introduction:}

Worldwide, reproductive health of women is considered an issue of vital importance and one that has wide spread implications on health (1). Gynecological health considers very important aspect of women health promotion. Awareness of gynecological health is very important for women, every women should learn what a normal and to know what changes to look out to detect any abnormality for gynecological health, of symptoms gynecological disease and methods of treatment (2).
Hysterectomy is a commonly performed surgical procedure that impacts on many aspects of a women's life. Removal of the uterus with or without conversation of the ovaries is often threatens woman's femininity, and produce a sense of incompleteness and distortion of the body image (3). In fact, the majority of hysterectomies are performed to treat nonmalignant conditions, to enhance the quality rather than save life. Quality enhancement of life (QEOL) was showed during the early years after hysterectomy(4). 
Hysterectomy remain the commonest elective major operation in the world with nearly 600,000 procedures being performed annually in the USA while more than 70,000 have hysterectomies each year in England alone. In the most countries at least $70 \%$ of hysterectomies are performed abdominally despite evidence that is feasible to achieve vaginal hysterectomy rates of between $77 \%$ and $88 \%$ (5). In Egypt annual diagnosis rate or the number of new cases of Hysterectomy diagnosed each year was 165,000 hysterectomies, about $40 \%$ of these for dysfunctional uterine bleeding with no gynecological pathology (6).

Hysterectomy can affect many aspects of a woman's health, the complications can result in mild-to severe morbidity. Women undergoing hysterectomy have numerous physiological, emotional and sexual changes that make them susceptible to experiencing emotional disorder which increase level of anxiety and depression in these women (7).

Coping pattern can be identified as a deliberate, planned and psychological effort to manage stressful demands, the coping process may inhibit or override the innate urge to act. Positive coping leads to adaptation, which is characterized by a balance between health and illness, a sense of wellbeing and maximum social functioning. When the women does not cope positively, mal adaptation occur that can shift the balance towards illness, a diminished self-concept and deterioration in social functioning (8). The coping pattern employed by women are closely aligned to spirituality, which motivates them to live through experience and overcome weaknesses and feelings of uncertainty (9).

Significance of the study:

Hysterectomy is one of the most common types of elective surgeries for the women. It is come into wide spread use in the early 20th century, it is consider second only to cesarean sections as the most frequently performed major operation in the United States. Rate of hysterectomy vary significantly among regions, rates are highest in the South and Midwest, and are higher for AfricanAmerican women. In recent years, although the number of hysterectomies performed declined, the number of hysterectomies performed on younger women aged 30-40 years increasing, and $55 \%$ of all hysterectomies are performed during 35-49years (10).

In Egypt annual diagnosis rate or the number of new cases of Hysterectomy diagnosed each year was 165,000 hysterectomies, about $40 \%$ of these for dysfunctional uterine bleeding with no gynecological pathology (11).

Aim of the study:

This study was done to investigate coping among women undergoing hysterectomy

\section{Research Questions}

-What are the women's concept and misconcept regarding hysterectomy?

-What is the coping style the woman was used undergoing hysterectomy?

\section{Subjects and methods:}

Research design:

A descriptive design was used to achieve the aim of the study.

\section{Research Setting:}

This study was this study was conducted at obstetric and gynecological department and gynecological clinic at Benha University hospital

\section{Subjects:}

A purposive sample of 100 women undergoing hysterectomy was included in the study according to the inclusion criteria. Who agrees to participate in the study, free from any chronic illness that affects women coping pattern, didn't receiving chemotherapy and radiotherapy. 


\section{Inclusion criteria:}

- Who agrees to participate in the study

- Free from any chronic illness that affect women coping pattern.

- Didn't receiving chemotherapy and radiotherapy.

\section{Tools for Data Collection:}

Two tools were piloted and used by the researcher to collect data including:

I) structured interviewing schedule: which includes three parts:

Part 1) General characteristics of the studied women included age, level of education, residence, marital status and occupation).

Part 2) Obstetric history include (number of pregnancies date of admission, indications of hysterectomy, and type of hysterectomy operation, number of deliveries, number of abortions and number of living children).

Part 3) Previous gynecological operations, gynecological history, current surgical procedure, occurrence of complication from hysterectomy.

II) This tool was designed to evaluate of women knowledge regarding hysterectomy. it consisted of (13) items, meaning of hysterectomy, types of hysterectomy, methods of performing hysterectomy, indications of performing hysterectomy, complications of hysterectomy, post-hysterectomy physical changes, post-hysterectomy psychological changes, exercise should done posthysterectomy, the best time to start exercise, physical care after hysterectomy, the best time to resume sexual intercourse, dangerous symptoms that require medical advice and the importance of follow up post-hysterectomy.

\section{Scoring:}

A correct answer was scored (2) and incorrect (1). The knowledge regarding hysterectomy calculated by adding the scores for the correct answer. The total possible score ranged from 13 to 26 .

Total incorrect answer $\quad<60.0 \%$

Total correct answer
III) Jalowiec coping scale (JCS): Jalowiec coping scale was adopted from Jalowiec, (1984) and modified by the researcher and translated into Arabic to evaluate the coping styles of women with hysterectomy. It was consisted of 60 items, classified into which eight coping styles as:

- Optimistic coping style (9) items. As positive thinking, positive outlook and positive comparisons.

-Fatalistic coping style (4) items. As pessimism, hopelessness and feeling of little control over the situation.

-Emotive coping style (5) items. As expressing and releasing emotions and venting feelings.

-Palliative coping style (7) items. As try to reduce or control distress by making the women feel better.

-Confirmative coping style (10) items. As confront the situation, face up to the problem and constructive problemsolving.

-Evasive coping style (13) items. As evasive and avoidant activities are used in coping with a situation.

-Supportive coping style (5) items. As using support systems such as personal, professional and/or spiritual.

-Self-reliant coping style (7) items. As depend on self rather than others in dealing with situations.

Scoring system:

JCS was rated on a 3- point likert scale from(1) never used; (2)sometime used; (3)often used. Then, summing up the scores of the items in each category and the overall scores gave the coping style score. The mean and standard deviation was calculated.

\section{Pilot study:}

A pilot study was carried out on $10 \%$ from the total number of sample (100) women to assess the objectivity, clarity and feasibility of the tools. As well as to estimate the time needed for data collection. Those women in the pilot study 
were not included in the main study sample since no modifications were done.

\section{Operational Design:}

The operational design for the study was included preparatory phase, pilot study, field work of the study.

Preparatory Phase:

It was included reviewing of national and international related literature using journals, magazine, periodicals, textbooks, and internet in order to develop the data collection tools.

Content Validity and Reliability:

There tools of data collection were assessed by three expertise of maternal nursing to assess content validity.

Administrative design:

An official letter was sent from the Dean of the Faculty of Nursing at Benha University to the director of Benha University Hospital explaining the aim of the study and the time of data collection to official permission was obtained for data collection.

\section{Ethical consideration:}

- Each woman was informed about the purpose and benefits of the study at the

Results:

Table : (1) Frequency distribution of the studied women according to their socio demographic characteristics $(n=100)$

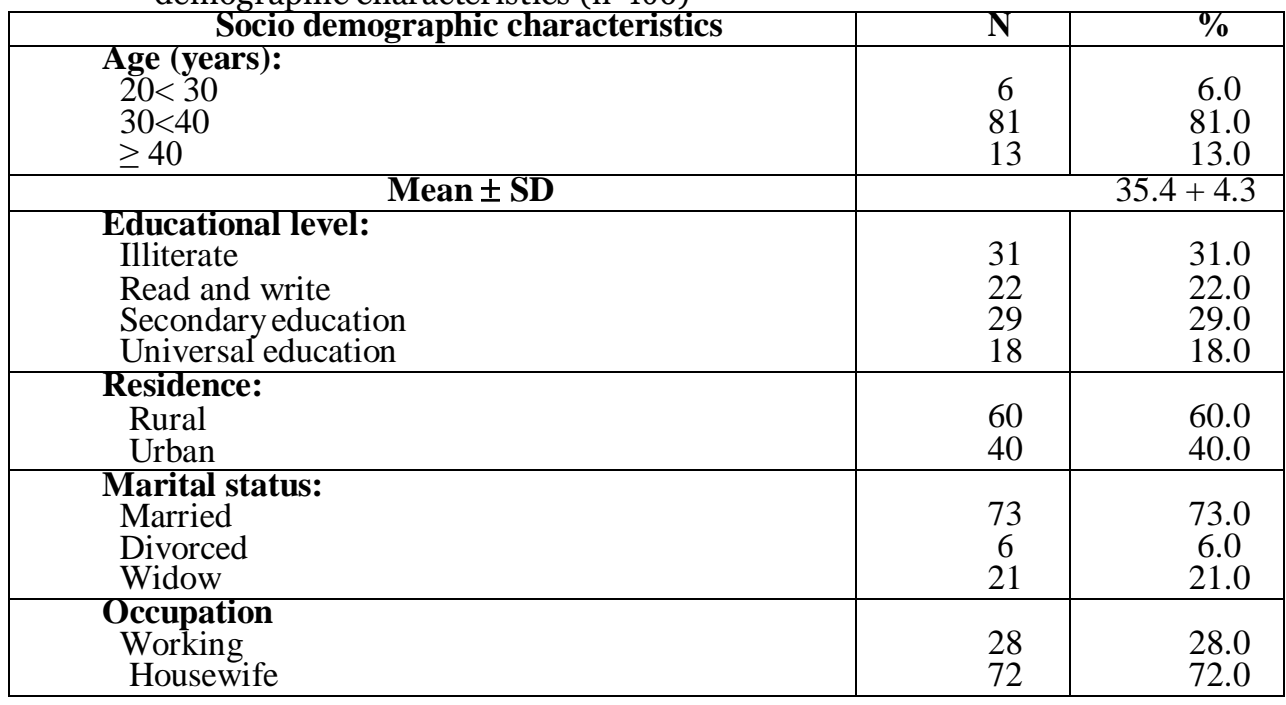

beginning of interview and time throughout the study.

- An oral consent was obtained from each woman before starting data collection.

- Confidentiality was ensured throughout the study process, where personal data were not disclosed, and the women were assured that all data was used only for research purpose. participation is voluntary and withdrawal will not affect her care.

\section{Statistical analysis}

Data analysis:

All data collected were organized, entered and analyzed by using the Statistical Package for Social Science (SPSS version 16). Descriptive statistics were applied (e.g., frequency, percentage, mean, standard deviation. Test of significance was used (Chi- square Test) to investigate relation between study variables. A significant level value was considered when $\mathrm{P} \leq 0.05$ and high significant differences obtained at $\mathrm{p}$ value $\leq 0.001$.
- Each woman was informed that 
Table (1) shows that $81.0 \%$ of the studied women have aged ranged from $30<40$ years old with the mean age $35.4 \pm 4.3$ years. Regarding educational level, less than one third of them $31.0 \%$ were illiterate, $60.0 \%$ of the studied women were lived in rural, Less than three quarters of them $73.0 \%$ were married, as well as less than three quarters $72.0 \%$ were housewives.

Table : ( 2) Frequency distribution of the studied women according to their obstetric and gynecological history $(n=100)$

\begin{tabular}{|l|c|c|}
\hline \multicolumn{1}{|c|}{ Obstetric history } & No. & $\%$ \\
\hline Number of pregnancies: & 1 & 1.0 \\
Non & 3 & 3.0 \\
Once & 14 & 14.0 \\
Twice & 31 & 31.0 \\
Three & 51 & 51.0 \\
\hline Three & & \\
\hline Number of deliveries: & 2 & 2.0 \\
Non & 5 & 5.0 \\
One & 22 & 22.0 \\
Two & 37 & 37.0 \\
Three & 34 & 34.0 \\
\hline Three & & \\
\hline Number of abortions: & 71 & 71.0 \\
Non & 18 & 18.0 \\
One & 9 & 9.0 \\
Two & 2 & 2.0 \\
\hline Two & 91 & 75.0 \\
\hline Number of living children* & & 91.0 \\
Male & & \\
Female & & \\
\hline Response are not mutually & & \\
\hline
\end{tabular}

* Response are not mutually exclusive

Table (2) reveals that, more than half of the studied women $51.0 \%$ were pregnant more than three times, $37.0 \%$ of them were delivered three times. Less than three quarters $71.0 \%$ of the women were not having abortion. As regarding number of living children, $75.0 \%$ were have male children compared to the majority of women $91.0 \%$ have female children. 
Ekram Sabry Mostafa et. al.

Table : ( 2) Frequency distribution of the studied women according to their obstetric and gynecological history $(\mathrm{n}=100)$

\begin{tabular}{|l|c|c|}
\hline \multicolumn{1}{|c|}{ Obstetric history } & No. & \% \\
\hline Number of pregnancies: & 1 & 1.0 \\
Non & 3 & 3.0 \\
Once & 14 & 14.0 \\
Twice & 31 & 31.0 \\
Three & 51 & 51.0 \\
> Three & & \\
\hline Number of deliveries: & 2 & 2.0 \\
Non & 5 & 5.0 \\
One & 22 & 22.0 \\
Two & 37 & 37.0 \\
Three & 34 & 34.0 \\
>Three & & 71.0 \\
\hline Number of abortions: & 71 & 18.0 \\
Non & 18 & 9.0 \\
One & 9 & 2.0 \\
Two & 2 & \\
>Two & & 75.0 \\
\hline Number of living children* & 75 & 91.0 \\
Male & 91 & \\
Female & & \\
\hline
\end{tabular}

* Response are not mutually exclusive

Table (2) reveals that, more than half of the studied women $51.0 \%$ were pregnant more than three times, $37.0 \%$ of them were delivered three times. Less than three quarters $71.0 \%$ of the women were not having abortion. As regarding number of living children, $75.0 \%$ were have male children compared to the majority of women $91.0 \%$ have female children.

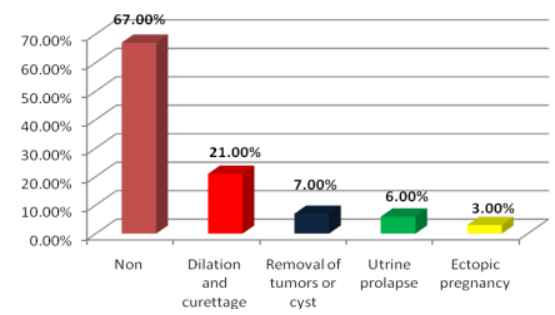

Figure (1): Frequency

distribution of the studied women according to previous

gynecological operations $(\mathrm{n}=100)$ 
INVESTIGATE COPING AMONG WOMEN UNDERGOING HYSTERECTOMY

Table (3): Frequency distribution of the studied women according to their gynecological history $(n=100)$

\begin{tabular}{|l|c|c|}
\hline \multicolumn{1}{|c|}{ Gynecological history } & $\mathbf{N}$ & $\boldsymbol{\%}$ \\
\hline Bleeding & 51 & 51.0 \\
Cancer in adenomyosis leiomyomas & 42 & 42.0 \\
Inflammatory disease & 5 & 5.0 \\
Ectopic pregnancy & 2 & 2.0 \\
Duration of treatment before hysterectomy(years) & & \\
<1 years & 48 & 48.0 \\
1-2years & 39 & 39.0 \\
2-3years & 5 & 5.0 \\
>3years & 8 & 8.0 \\
\hline \multicolumn{2}{c|}{} \\
\hline
\end{tabular}

Table (3) displays that, $51.0 \%$ of the studied women suffered from bleeding. Meanwhile only $2.0 \%$ had ectopic pregnancy. The mean duration of treatment before hysterectomy $1.8 \pm 1.2$ year.

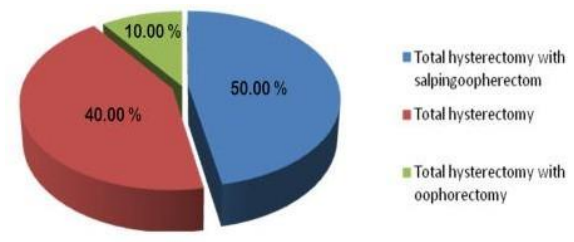

Figure (II): Frequency distribution of studied women according to current surgical procedure $(n=100)$

Figure (2): it was observed that, $50.0 \%$ of the studied women were had total hysterectomy with salpingoopherectomy.

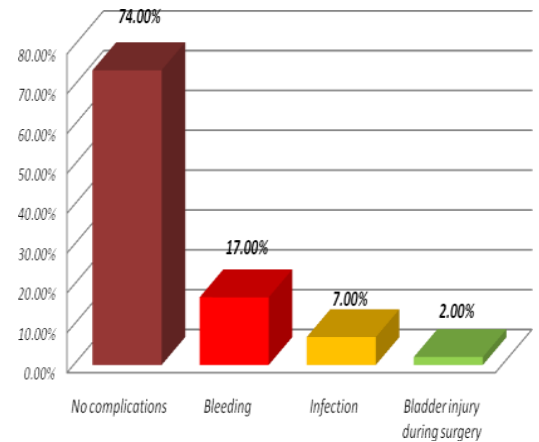

Figure (3): Frequency distribution of studied women according to occurrence of complications from hysterectomy $(n=100)$

Figure (3) shows that, less than three quarters of the studied women $74.0 \%$ were had no complications from hysterectomy procedure. 
Table (4): Frequency distribution of studied women according to knowledge about hysterectomy $(n=100)$

\begin{tabular}{|l|c|c|}
\hline \multirow{2}{*}{ Items } & Correct answer & Incorrect answer \\
\cline { 2 - 3 } & \% & \% \\
\hline Meaning of hysterectomy & 45.0 & 55.0 \\
Methods of performing hysterectomy & 19.0 & 81.0 \\
Indications of hysterectomy & 20.0 & 80.0 \\
Complications of hysterectomy & 12.0 & 88.0 \\
Post-hysterectomy physical changes & 8.0 & 92.0 \\
Post-hysterectomy psychological changes & 9.0 & 91.0 \\
Self-care post hysterectomy:- & 1.0 & 99.0 \\
Exercise should done post-hysterectomy & 7.0 & 93.0 \\
The best time to start exercise & 37.0 & 63.0 \\
Physical care after hysterectomy & 10.0 & 90.0 \\
The best time to initiate sexual intercourse & 23.0 & 77.0 \\
Dangerous signs require medical advice & 25.0 & 75.0 \\
The importance of follow up post- & & \\
hysterectomy & \\
\hline
\end{tabular}

Table (4) demonstrates that majority of the studied women $90.0 \%, 91.0 \%$, $92.0 \%, 93.0 \%$ and $99.0 \%$ were had incorrect knowledge regarding to the best time to resume sexual intercourse, exercise should done post-hysterectomy, posthysterectomy physical changes, the best time to start exercise, and posthysterectomy psychological changes respectively. As well as more than three quarters of them $75.0 \%, 77.0 \%, 80.0 \%$ and $88.0 \%$ had incorrect knowledge regarding to the importance of follow up post-hysterectomy, dangerous symptoms that require medical advice, the indications of hysterectomy and complications of hysterectomy respectively.

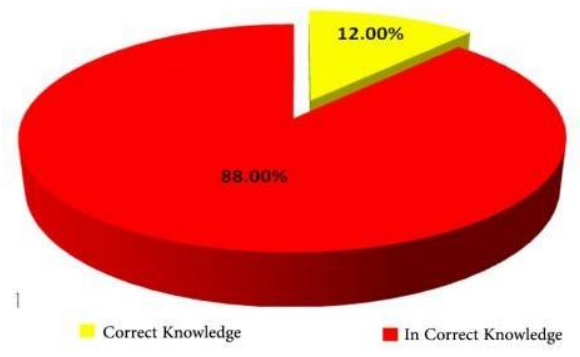

Figure (IV): Frequency distribution of studied women according to their total knowledge score $(n=100)$

Figure (4) reveals that most of the studied women $88.0 \%$ were had incorrect knowledge score regarding hysterectomy compared to $12.0 \%$ had correct knowledge. 
INVESTIGATE COPING AMONG WOMEN UNDERGOING HYSTERECTOMY

Table (5): Relation between total coping styles and total knowledge of the studied women $(\mathrm{n}=100)$

\begin{tabular}{|c|c|c|c|c|c|c|}
\hline \multirow{3}{*}{ Total coping styles } & & & & & \multirow{3}{*}{$X^{2}$} & \multirow{3}{*}{$P$ value } \\
\hline & \multicolumn{2}{|c|}{$\begin{array}{c}\text { Incorrect answer } \\
=\mathbf{8 8}\end{array}$} & \multicolumn{2}{|c|}{$\begin{array}{c}\text { Correct answer } \\
=12\end{array}$} & & \\
\hline & N. & $\%$ & $\mathrm{~N}$. & $\%$ & & \\
\hline $\begin{array}{l}\text { Optimistic coping style } \\
\text { Low } \quad(N .=72) . \\
\text { Moderate }(\mathrm{N} .=28) . \\
\text { High } \quad(\mathrm{N} .=0) .\end{array}$ & $\begin{array}{c}27 \\
60 \\
1\end{array}$ & $\begin{array}{c}30.7 \\
68.2 \\
1.1\end{array}$ & $\begin{array}{c}0 \\
11 \\
1\end{array}$ & $\begin{array}{c}0 \\
91.7 \\
8.3\end{array}$ & 7.237 & $>0.05$ \\
\hline $\begin{array}{l}\text { fatalistic coping style } \\
\text { Low } \quad\left(\mathrm{N}_{.}=50\right) . \\
\text { Moderate }(\mathrm{N} .=50) \\
\text { High } \quad(\mathrm{N} .=0)\end{array}$ & $\begin{array}{l}17 \\
43 \\
28 \\
\end{array}$ & $\begin{array}{l}19.3 \\
48.9 \\
31.8 \\
\end{array}$ & $\begin{array}{l}0 \\
7 \\
5\end{array}$ & $\begin{array}{c}0.0 \\
58.3 \\
41.7\end{array}$ & 2.818 & $>0.05$ \\
\hline $\begin{array}{ll}\text { Emotive coping style } \\
\text { Low } & (\mathrm{N} .=95) . \\
\text { Moderate } & (\mathrm{N} .=4) . \\
\text { High } & (\mathrm{N} .=0) .\end{array}$ & $\begin{array}{l}85 \\
2 \\
1\end{array}$ & $\begin{array}{c}96.6 \\
2.3 \\
1.1 \\
\end{array}$ & $\begin{array}{l}10 \\
2 \\
0\end{array}$ & $\begin{array}{c}83.3 \\
16.7 \\
0 \\
\end{array}$ & 5.801 & 0.055 \\
\hline $\begin{array}{l}\text { Palliative coping style } \\
\text { Low } \quad(\mathrm{N} .=72) . \\
\text { Moderate }(\mathrm{N} .=28) . \\
\text { High } \quad(\mathrm{N} .=0) .\end{array}$ & $\begin{array}{c}54 \\
34 \\
0\end{array}$ & $\begin{array}{c}61.4 \\
38.6 \\
0\end{array}$ & $\begin{array}{l}4 \\
7 \\
1\end{array}$ & $\begin{array}{c}33.3 \\
58.3 \\
8.3\end{array}$ & 9.763 & $<0.001 * *$ \\
\hline $\begin{array}{l}\text { Confirmative coping style } \\
\text { Low } \quad(\mathrm{no}=64) . \\
\text { Moderate }(\mathrm{no}=36) . \\
\text { High } \quad(\mathrm{N} .=0) .\end{array}$ & $\begin{array}{c}61 \\
27 \\
0\end{array}$ & $\begin{array}{c}69.3 \\
30.7 \\
0\end{array}$ & $\begin{array}{l}3 \\
9 \\
0\end{array}$ & $\begin{array}{c}25.0 \\
75.0 \\
0\end{array}$ & 9.002 & $<0.001 * *$ \\
\hline $\begin{array}{l}\text { Evasive coping style } \\
\text { Low } \quad(\mathrm{N} .=83) . \\
\text { Moderate }(\mathrm{N} .=16) . \\
\text { High } \quad(\mathrm{N} .=1) .\end{array}$ & $\begin{array}{c}37 \\
50 \\
1 \\
\end{array}$ & $\begin{array}{c}42.0 \\
56.8 \\
1.1 \\
\end{array}$ & $\begin{array}{l}4 \\
7 \\
1 \\
\end{array}$ & $\begin{array}{c}33.3 \\
58.3 \\
8.3 \\
\end{array}$ & 2.935 & $>0.05$ \\
\hline $\begin{array}{l}\text { Supportive coping style } \\
\text { Low } \quad(\mathrm{N} .=16) . \\
\text { Moderate }(\mathrm{N} .=42) . \\
\text { High } \quad(\mathrm{N} .=42) .\end{array}$ & $\begin{array}{c}6 \\
35 \\
47 \\
\end{array}$ & $\begin{array}{c}6.8 \\
39.8 \\
53.4 \\
\end{array}$ & $\begin{array}{l}2 \\
2 \\
8 \\
\end{array}$ & $\begin{array}{l}16.7 \\
16.7 \\
66.7 \\
\end{array}$ & 3.142 & $>0.05$ \\
\hline $\begin{array}{l}\text { Self-reliant style } \\
\text { Low } \quad\left(\mathrm{N}_{.}=97\right) \\
\text { Moderate }(\mathrm{N} .=3) \\
\text { High } \quad(\mathrm{N} .=0)\end{array}$ & $\begin{array}{c}22 \\
58 \\
8\end{array}$ & $\begin{array}{c}25.0 \\
65.9 \\
9.1 \\
\end{array}$ & $\begin{array}{l}1 \\
6 \\
5\end{array}$ & $\begin{array}{c}8.3 \\
50.0 \\
41.7\end{array}$ & $\begin{array}{l}10.31 \\
3\end{array}$ & $\leq 0.005 * *$ \\
\hline
\end{tabular}

Table (5), demonstrates that there is no statistically significant relation between women's knowledge and fatalistic, evasive and supportive coping styles, while there is a statistical significant relation between women's knowledge and optimistic coping and emotive coping styles. there is highly a statistical significant relation between women's knowledge and palliative, confirmative and self-reliant coping styles. 
Ekram Sabry Mostafa et. al.

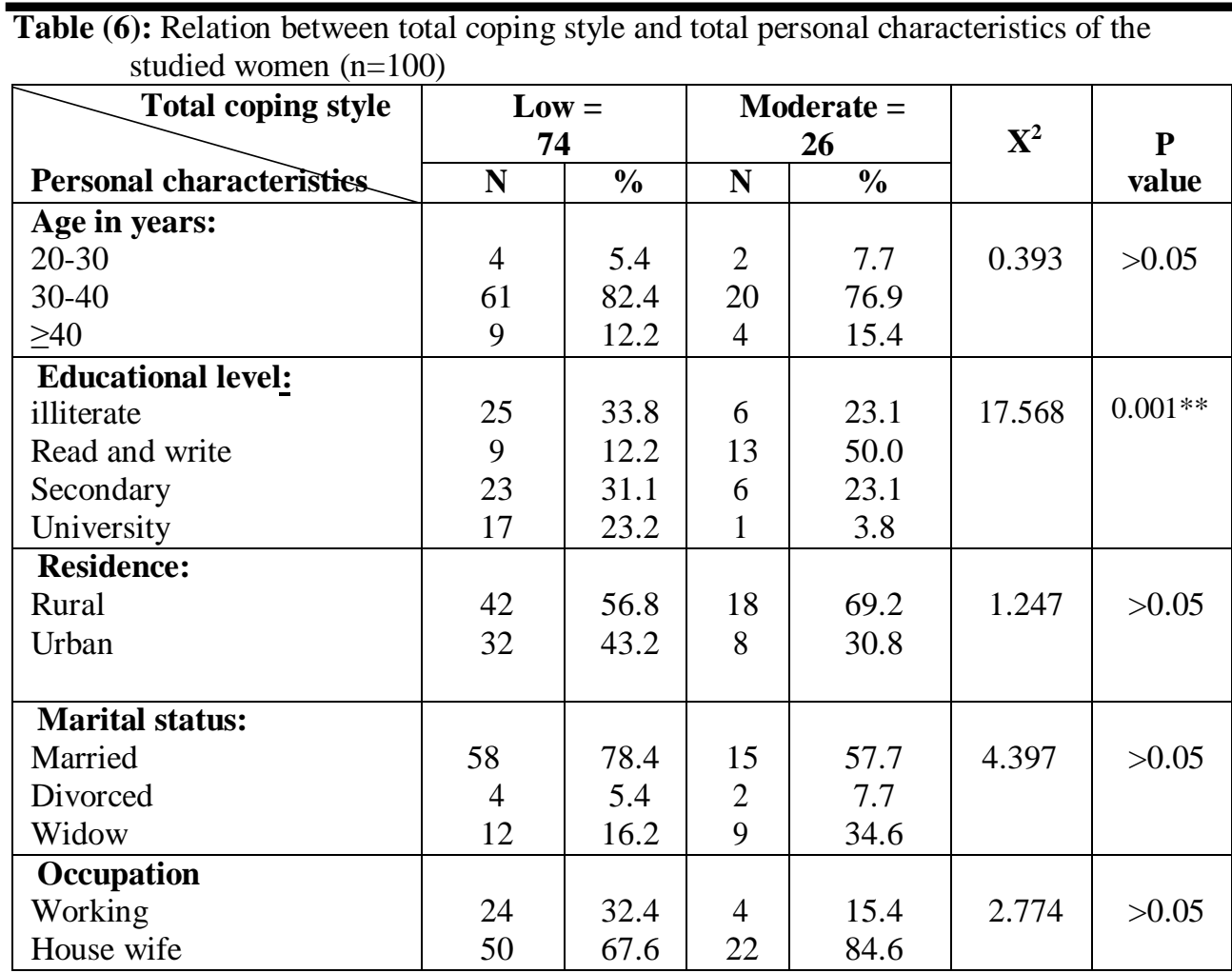

Table (6): Illustrates that there was highly statistical significant differences between total coping and women personal characteristics.

\section{Discussion:}

The finding of present study found that. The most of studied women have aged ranged from $(30<40)$ years old with the mean age of $35.4 \pm 4.3$ years. This finding is in contrast with (12) who found that majority of study subjects were have a hysterectomy by age (55). Moreover, (13) reported that, the mean age of the studied women undergoing was 49. 50 years \pm 14.35 with most common age group being 41-55 years. However this result is agreeing with (14), reported that hysterectomy tends to occur in midlife. Especially when the women are still premenopausal mean age of the study sample was $49.8 \pm 8.4$ for the study group. Concerning the educational level, more than half of the studied women were illiterate and read and write. This is in agreement with (15), who found that hysterectomy prevalence tended to be higher among women with lower school degrees. This may be attributed to difference

In population structure and methods of case selections.According to the present study finding, less than two third of women were lived in rural area where there is lack of health facilities and no periodical checkup for early detection of the disease. Where traditional beliefs still have strong influence on most interviewed women about the importance of follow up. This is supported by (16), who reported that incidence rate of most hysterectomy is lower among residents of urban areas than residents of rural areas.

In relation to marital status, the study findings showed that, less than three quarter of the studied women were 
married, housewives. In agreement with this finding (17), who found that the majority of the studied women were married and housewives. This findings are in same line with (18), who reported that most of studied women were married and were housewives

Concerning obstetric and gynecological history, the findings of present study revealed that more than half of studied women were pregnant more than three times, while more than one third were delivered three times. This might be due to Egyptian culture about early marriage of the female and increase fertility rate in Egypt. In congruence with this finding, a study of (19) about risk factors for hysterectomy in Northeastern Thailand showed that most of the studied women have more than three times deliveries. These finding also supported by (20), who pointed out that the relation of hysterectomy and number of previous births that is rate of hysterectomy was higher among women who had higher rate of previous births.

As regard to the history of abortion, the findings of the present study revealed that less than three quarter of the studied women were had not positive history of abortion, this finding is in line with (21), found that the majority of studied women have no abortion.

Meanwhile, more than two thirds of the studied women were have not any previous gynecologic operations. This is in agreement with (22) who emphasized the about half of women undergoing hysterectomy not have any gynecological operations before hysterectomy.

Regarding gynecological history, the finding of the present study revealed that more than half of the studied women suffered from bleeding and discovered the disease when they sought medical advice for this symptom. Which may be due to living far away from hospital may present an obstacle against periodic follow up visits. This is in agreement with (23), who emphasized that discovery of the disease was by the presence of bleeding.

Regarding to the type of hysterectomy, the finding of the current study revealed that half of the studied women have hysterectomy with salpino ophorectomy and only ten percent of them have total hysterectomy with oophorectomy. This is in accordance with (24), reported that the rate of hysterectomy with oophorectomy was $12.2 \%$. On the other hand (25) reported that $89 \%$ of hysterectomies women have total hysterectomy with conservation of one or both ovaries.

As regard to occurrence of complications from hysterectomy, the finding of the current study revealed that less than three quarters of the studied women were had no complications from hysterectomy procedure this is supported by (26) who reported that, only three percent of the studied women have postoperative complications.

As regarding to the first research question (what are women correct knowledge regarding hysterectomy), the finding of the present study revealed that most of the studied women $(45 \%)$ had correct answer regarding meaning of hysterectomy. While $(80 \%, 88 \%$, ) of the studied women had incorrect answer about indications of hysterectomy and complications, also the majority of studied women had incorrect answer about post-hysterectomy physical changes, Post-hysterectomy psychological changes, Exercise should done post-hysterectomy, The best time to start exercise and The best time to resume sexual intercourse, addition to, about three quarters of the studied women, had unsatisfied knowledge about the importance of follow up posthysterectomy. This may reflect the deficiencies in health institutions 
regarding their role toward health education and this might be due to majority of studied women are from rural areas with less attention to acquisition of knowledge, due to most of the studied women were illiterate also due to health team overload and the neglect to provide the women with health education and information needed for their disease. This finding is in agreement with (26) who found that the majority of the studied women had unsatisfied knowledge on various aspects as meaning of hysterectomy and methods of performing hysterectomy. Moreover this finding is in agreement with (27), who found that the majority of studied subject had unsatisfied knowledge about these items. On other hands this finding was consistent with (28) who showed that most of the studied women had deficient knowledge about hysterectomy. This lack of knowledge can be attributed to the lack of educational programs and unavailability of information resources about the operation. It reflects a deficiency in providers' educational role.

Regarding the second study questions which was (what are the coping style was used for women undergoing hysterectomy) the optimistic coping style was moderately used by the women in the current study. The rate of the use of this style varied by item. The item that was most commonly used was the "tried to see the good side of the situation" being often used by more than half of the women with additional to "Thought about the good things in life" and "compared self with other people who were in the same situation" these items never used by the women. These findings indicate that the optimistic coping styles moderate use to maintain positive approaches to women lives and thus can deal with the challenges of hysterectomy in unacceptable way. These result is consistent with (29) reported that, hysterectomy had serious distress on the physical, social and psychological aspects of the women's life, still some women use the optimistic coping that gives the sense of hope for a better future and minimize the psychological pressure. This inconsistent with (30) found high using optimistic coping only when the event was construed as uncontrollable.

Regarding the relation between total coping styles and total knowledge of the studied women, this result revealed that no statistically significant relation between women's knowledge and fatalistic, evasive and supportive coping styles, while there is a statistical significant relation between women's knowledge and optimistic coping and emotive coping styles. There is highly a statistical significant relation between women's knowledge and palliative, confirmative and self-reliant coping styles. This finding was in accordance with (31) who reported no statistical significant relation between women's knowledge and fatalistic, evasive, supportive, while there is a statistical significant relation between women's knowledge and optimistic coping styles.

\section{Conclusion:}

The current study concluded that, Hysterectomy have more effect on women's coping pattern. Most of women have worried about hysterectomy and got mad and let off steam. Majority of women prayed or put her trust in God, minority of the studied women never use accepted the situation because very little could be done as supportive coping style respectively, and thought about how handled other problems in the past " as self-reliant coping style respectively .Mean while three quarters of women never use eat or smoked more than usual and also never use avoided being with people. 
Recommendations:

Based on the results the current

study the following recommended can be:

1. Establish education, counseling, and rehabilitation programs for women with hysterectomy to improve coping pattern.

2. Continuous monitoring and evaluating coping pattern for women undergoing hysterectomy to early detecting and solving any problems.

3. The importance of design and implementing guidelines to enhance women practices for management of post hysterectomy care.

4. Disseminations of presented research finding to all gynecological department at Benha government.

5. Further research to evaluate mal practices for women undergoing hysterectomy

\section{References:}

Ricci S.S (2010): Essentials of maternity, newborn and woman's health nursing, anatomy and physiology of female reproductive organs and woman's heath throughout the life span, $8^{\text {th }}$ ed., Lippincott Williams and Wilkins, Philadelphian, London,pp.45-97,p.162

Ricket S. (2011): Quality of life and factors affecting response to hysterectomy. Journal of family practice 7: (18).

Danfoth D.N. and Scott J.R (2013): obstetrics and gynecolog, perioperative care, $12^{\text {th }}$, Philaelpia, Harper and row, pp.210, 791.

Roesk N.C.A (2010): Hysterectomy and quality of woman's life. Intern Med, 139(4): 146-147.

Hospital Episode Statistics England (2011): Department of Health. 5, (1) London : HMSO.

Abrams P, Cardozo L, Fall M, and et al., (2012): The standardisation of terminology of lower urinary tract function: report from the Standardisation
Subcommittee of the International Continence Society. Neurourol Urodyn , 21: 167-178.

Sabbour S., (2010): Epidemiological correlates of hysterectomy, a hospital based study at Ain Shams Maternity Hospital. Jour. Egypt Health Assoc, 76(12): 71-87.

Ryan M. (2011): Hysterectomysocial and psychosexual aspect. Journal of Billieries clinical obstetric and gynecolog: 30 (4)

43-5.

Berannan M. (2013): Study of hysterectomy in famly practie. The Journal of family practice, 8(4):723-9.

Jacofsky R., and Matthew L. (2011): The Maintenance of Anxiety Disorders: Maladaptive Coping Strategies. Available at: www.seabhs.org/poc/view.Accessed on:14-12-2013.

Clarke A., and Black N. (2014): Indications for and outcomes of total hysterectomy for benign disease: Prospective cohort study. Obstetrics and gynecology Scand.83 (2):191-6.

Carlson K. (2013): The Maine Women"s Health Study: 1. Outcome of hysterectomy. Obstet Gynecol, 3: 556.

Stang A., Merrill R.M., Kuss O. (2011): Nationwide rates of conversion from laparoscopic or vaginal hysterectomy to open abdominal hysterectomy in Germany. Eur J Epidemiol. 26:125-133. doi: 10.1007/s10654-010-9543-4. [Pub Med] [Cross Ref].

Lippe E., Scheidt C., Starker A., and Fuchs J. (2013): Prevalence of hysterectomy in women 18 to 79 years old: results of the German Health Interview and Examination Survey for Adults (DEGS1).

Bundesgesundheitsblatt

Gesundheitsforschung

Gesundheitsschutz, 56(56):716-22.

American College of Obstetricians and Gynecologists practice (2014): bulletin. Alternatives to hysterectomy in the 
management of leiomyomas. Obstet Gynecol. 112:387-400. [Pub Med] [Cross Ref

hMarks N.F. (2105): Socioeconomic differences in hysterectomy: the Wisconsin longitudinal study. Am J Public Health. 1997; 87: 1507-1514. doi: $\quad 10.2105 /$ AJPH.87.9.1507. [PMC

free article] [Pub Med] [Cross Ref].

Bernhard L.A. (2012): Consequences of hysterectomy in the lives of women. Health Care Women 13(3):281-291.

Lucke J., Lawlor D.A., Mishra G., and et al. (2013): Socioeconomic position and hysterectomy: a cross-cohort comparison of women in Australia and great Britain. J Epidemiol Community Health. 10571063. doi: 10.1136/jech.2013.071001.

Carlson K. (2013): The Maine Women"s Health Study: 1. Outcome of hysterectomy. Obstet Gynecol, 3: 556.

Natphopsuk S., Ishida W., Sinawat S., and et al. (2012): Risk Factors for Cervical Cancer in North-eastern Thailand: Detailed Analysis of Sexual and Smoking Behavior. Asian Pacific Journal of Cancer Prevention, 13 (11), 5489-5495.

Prütz F., Knopf H., Lippe E., and et al, (2013): Prevalence of hysterectomy in women 18 to 79 years old: results of the German Health Interview and Examination Survey for Adults (DEGS1). 56(5-6):716-22.

Raychaudhuri S., and Mandal S. (2012): Socio-Demographic and Behavioral Risk Factors for Cervical Cancer and Knowledge, Attitude and Practice in Rural and Urban Areas of North Bengal, India. Mandal Asian Pacific Risk Factors for Cervical Cancer and Knowledge, Attitude and Practice in Rural and Urban Areas of North Bengal, India. Mandal Asian Pacific Journal of Cancer Prevention, 13: 1093-1096.

Kain K.H. (2010): Symptom experience in women after hysterectomy. Journal of Obstetric, Gynecologic and Neonatal Nursing, 30 (5), 472-480.

Harlow B.L. (2015): Influence of education on risk of hysterectomy before age 45 years. Am J Epidemiol. 150:843- 847. doi: 10.1093/oxfordjournals.aje.a010089.

[Pub Med] [Cross Ref].

Farquhar C.M., Harvey S.A., Sadler L., and et al., (2013): A prospective study of 3 years of outcomes after hysterectomy with and without oophorectomy. AMJ Obstet Gynecol. 194(3):711-7.

National Institute for Health and Clinical Excellence. (NICE). (2015): Clinical guideline 44: heavy menstrual bleeding. London: National Institute for Health and Clinical Excellence. 2-5-2011. Ref Type: Generic.

Ebrahim S. (2010): Lay perceptions of a "natural" menopause: cross sectional study of the British women's heart and health study. BJOG.109:1398-1400. doi: 10.1046/j.1471-0528.2002.02046.x. [Pub Med] [Cross Ref].

Gath D., Cooper P., Bond A., and et al., (2013): Hysterectomy and psychiatric disorder: II. Demographic, psychiatric and physical factors in relation to psychiatric outcome. BrJ Psychiatry .140:343 -350.

Kjerulff K.H. (2011): Patient satisfaction with results of hysterectomy. AMJ Obstet Gynecol. 183(6):1440-7.

Johnson N. (2010): Surgical approach to hysterectomy for benign gynecological disease (Review). Cochrane Database Syst Rev. (2):CD003677.

Webb C., and Wilson J., (2010): Selfconcept, social support and hysterectomy. International Journal of Nursing Studies, 20 (2), 97-107.

Shehmar M., (2011): The influence of psychological factors on recovery from hysterectomy. $103 \quad$ (2): $\quad$ 5659. Spielberger CD. 